\title{
Patterns of Primary Focal Segmental Glomerulosclerosis (FSGS) in Adults Treated in a Dakar Single Center: About 58 Cases
}

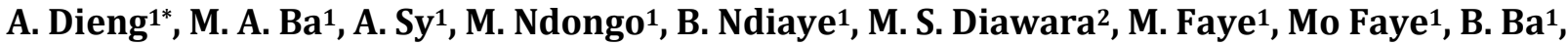 \\ N. Keita1 ${ }^{1}$, S. Diagne', C. Ouanekpone ${ }^{1}$, A. T. Lemrabott ${ }^{1}$, M. M. Cissé2 ${ }^{2}$ E. F. Ka ${ }^{1}$, A. Niang ${ }^{1}$ \\ ${ }^{1}$ Department of Nephrology, Dialysis and Kidney Transplant in Hospital Aristide Le Dantec, Dakar, Senegal \\ ${ }^{2}$ Department of Nephrology and Dialysis in Regional Hospital, Thies, Senegal \\ Email: *methjeng@gmail.com
}

How to cite this paper: Dieng, A., Ba, M.A., Sy, A., Ndongo, M., Ndiaye, B., Diawara, M.S., Faye, M., Faye, M., Ba, B., Keita, N., Diagne, S., Ouanekpone, C., Lemrabott, A.T., Cissé, M.M., Ka, E.F. and Niang, A. (2020) Patterns of Primary Focal Segmental Glomerulosclerosis (FSGS) in Adults Treated in a Dakar Single Center: About 58 Cases. Open Journal of Nephrology, 10, 265-273.

https://doi.org/10.4236/ojneph.2020.104026

Received: April 1, 2020

Accepted: October 13, 2020

Published: October 16, 2020

Copyright (๑) 2020 by author(s) and Scientific Research Publishing Inc. This work is licensed under the Creative Commons Attribution International License (CC BY 4.0).

http://creativecommons.org/licenses/by/4.0/

\begin{abstract}
Introduction: The evolution of primary FSGS is often marked by the occurrence of relapse and corticosteroid resistance and the therapeutic options are numerous and have limited effectiveness. The objective of our study was to assess our practice in this lesion. Patients and Methods: We carried out a retrospective study of patients treated for primary FSGS the period January 1 , 2010 to September 30, 2018. The clinical pathological, therapeutic and evolutive characteristics were studied. Results: Fifty-eight patients were included in the study. The average age was $30.74 \pm 11.35$ years and the sex ratio $(\mathrm{M} / \mathrm{F})$ was 2.41 . Edema was found in $86.2 \%$ and hypertension in $37.9 \%$. The average creatinine was $20.17 \pm 16.06 \mathrm{mg} / \mathrm{l}$ and the average GFR according to MDRD was $82.43 \pm 69.06 \mathrm{ml} / \mathrm{min} / 1.73 \mathrm{~m}^{2}$. The average albumin level was $15.11 \pm$ $5.78 \mathrm{~g} / \mathrm{l}$ and the 24 -hour proteinuria was $7.8 \pm 3.79 \mathrm{~g} / 24 \mathrm{~h}$. Nephrotic syndrome was the main indication for renal biopsy in $84.48 \%$ and the classic form of FSGS was found in $90.9 \%$. The average initial corticosteroid dose was $62.68 \pm 10.04 \mathrm{mg} / \mathrm{d}$ and the average duration of regression was $11.78 \pm 7.40$ months. Forty-five patients $(77.6 \%)$ were corticosensitive $(27.6 \%$ complete remission and $50 \%$ partial remission). Corticosteroid resistance was observed in $19 \%$ and corticosteroid dependence in $11.1 \%$. The proportion of relapse was $33.3 \%$ within an average of $15.4 \pm 9.1$ months. Cyclosporine was no longer prescribed as a second-line treatment in 8 patients. Infectious complications were more found in $19 \%$. Two patients had progressed to ESRD and we noted 2 death cases. The male gender was correlated with the occurrence of a relapse. However, the impact of certain factors such as hypertension, proteinuria, hematuria and GFR level has not been demonstrated. Conclusion: The evolution of primary FSGS is unpredictable, often marked by re-
\end{abstract}


lapses, hence the interest in identifying factors associated with therapeutic responses for better management.

\section{Keywords}

FSGS, Nephrotic Syndrome, Corticosteroid Resistance

\section{Introduction}

FSGS is a histopathological entity characterized by the presence of hyaline deposits, glomerular sclerosis and podocyte alteration often resulting in nephrotic syndrome. Although patients with primary FSGS may present a certain level of proteinuria, clinical concern is greater for those who present nephrotic-range proteinuria, because without treatment, they have an extremely poor prognosis, progressing to ESRD over the course of 3 to 6 years [1]. Therapeutic options are few and have limited effectiveness. Oral corticosteroid therapy is the first line of treatment, but only $50 \%$ to $60 \%$ will have complete remission [2]. Steroid-dependence, steroid-resistance and relapses are frequent and require a combination with immunosuppressive therapy [3]. The potential risk of CNI-induced nephrotoxicity and the cost of that therapy are a major deterrent for patients in developing countries [4]. The aim of our study was to assess our practice in relation to this lesion by determining the clinical, pathological, therapeutic and evolutive aspects.

\section{Patients and Methods}

It was a retrospective, cross sectional and analytical study from January 1, 2010 to September 30,2018, relating to the records of patients treated in nephrology department for FSGS. The diagnosis of primary FSGS was made before a histopathological entity characterized by the presence of hyaline deposits, glomerular sclerosis and podocyte alteration without any secondary cause such as a long standing hypertension, severe obesity, solitary kidney, reflux nephropathy, asymmetric kidneys and systemic disease. We included patients aged 18 years and over, on long-term treatment and having a follow-up period of at least 4 months. Secondary forms of FSGS and patients lost to follow-up were not included in the study. The data studied were age, gender, blood pressure, proteinuria, hematuria, anemia, azotemia, creatininaemia, GFR (according to MDRD) and albuminemia. Other characteristics such as indication for renal biopsy, type of FSGS and associated lesions were assessed. Oral corticosteroid therapy was administered to all patients at $1 \mathrm{mg} / \mathrm{kg} /$ day for 4 months. Immunosuppressive drugs were prescribed in second intention in combination with low doses of corticosteroids. We studied the evolution of proteinuria at 4, 8 and 12 months. Complete remission was defined by proteinuria $<0.3 \mathrm{~g} / 24 \mathrm{~h}$ and partial remission if this rate was between $0.3-3 \mathrm{~g} / 24 \mathrm{~h}$. Corticosteroid resistance was defined 
by an absence of regression of proteinuria after 12 to 16 weeks of corticosteroid treatment and corticosteroid dependence if an increase of proteinuria was observed during the reduction in doses of corticosteroids or within 2 weeks of stopping treatment. Relapse was considered to be an increase in proteinuria beyond $3 \mathrm{~g} / 24 \mathrm{~h}$ in a patient in remission [2].

The data was collected on patients' records with the ODK collect software version v1.18.2. The results were analyzed by Epi Info ${ }^{\mathrm{Tm}} 7.2$ software.

The data collected will be expressed in proportion (percentage) for the qualitative variables and on average followed by the standard deviation for the quantitative variables.

In univariate analysis, the proportions were compared using the Pearson or Fischer chi-square test according to their applicability condition. A significant association was retained if the $\mathrm{p} \leq 0.05$.

\section{Results}

During this period, 58 patients were treated for primary FSGS. The mean age was $30.7 \pm 11.3$ years. The sex ratio was 2.41 . Edema was found in $86.2 \%$ of patients and hypertension in $37.9 \%$. The mean proteinuria was $7.8 \pm 3.79 \mathrm{~g} / \mathrm{day}$ and albuminemia was $15.1 \pm 5.78 \mathrm{~g} / \mathrm{L}$ (Table 1 ).

Table 1. Characteristics of studied population.

\begin{tabular}{lc}
\hline Characteristics & Total patients $(\mathrm{n}=58)$ \\
Age (years) & $30.7 \pm 11.3[18-58]$ \\
Sex ratio (M/F) & 2.41 \\
Edema, $\mathrm{n}(\%)$ & $50(86.2)$ \\
High blood pressure, $\mathrm{n}(\%)$ & $22(37.9)$ \\
Blood urea (g/l) & $0.7 \pm 0.68$ \\
Creatininaemia (mg/l) & $20.2 \pm 16.06$ \\
GFR according to MDRD (ml/min/1.73 m²) & $82.4 \pm 69.06$ \\
Albuminemia (g/l) & $15.1 \pm 5.78$ \\
Hemoglobin (g/dl) & $11.8 \pm 2.49$ \\
Proteinuria (g/24 h) & $7.8 \pm 3.79$ \\
Types of HSF & \\
Classic (\%) & 90.9 \\
Tip lesion (\%) & 7.3 \\
Collapsing (\%) & 1.8 \\
Remission, $\mathrm{n}(\%)$ & $45(77.6)$ \\
CR, $\mathrm{n}(\%)$ & $16(27.6)$ \\
RP, $\mathrm{n}(\%)$ & $29(50)$ \\
Corticosteroid resistance, $\mathrm{n}(\%)$ & $11(19)$ \\
Relapse, $\mathrm{n}(\%)$ & $5(11.1 \%)$ \\
Corticosteroid dependence $\mathrm{n}(\%)$ & \\
\hline & \\
\hline
\end{tabular}


Nephroticsyndrom was the main indication for renal biopsy in $84.48 \%$ and the histological types found were the classic form (Figure 1), the tip-lesion form (Figure 2) and the collapsing form (Figure 3) respectively in $90.9 \%, 7.3 \%$ and $1.8 \%$. Vascular lesions were associated in $52.2 \%$ and tubulointerstitial lesions in $65.3 \%$.

RAAS inhibitors were prescribed in all eligible patients. First prescribed corticosteroid therapy was on average $62.7 \pm 10.04 \mathrm{mg} / \mathrm{d}$ for an average duration of $3.6 \pm 1.9$ months. The corticosteroid dose reduction lasted $11.8 \pm 7.4$ months.

In 58 patients, remission was obtained (in) $77.6 \%$. Complete remission (CR) was observed in 16 patients (27.6\%) and partial remission (PR) was observed in 29 patients (50\%). Eleven patients were corticosteroid-resistant (19\%). We noted 2 cases of death, one related to severe hypokalemia and the other to undetermined cause.

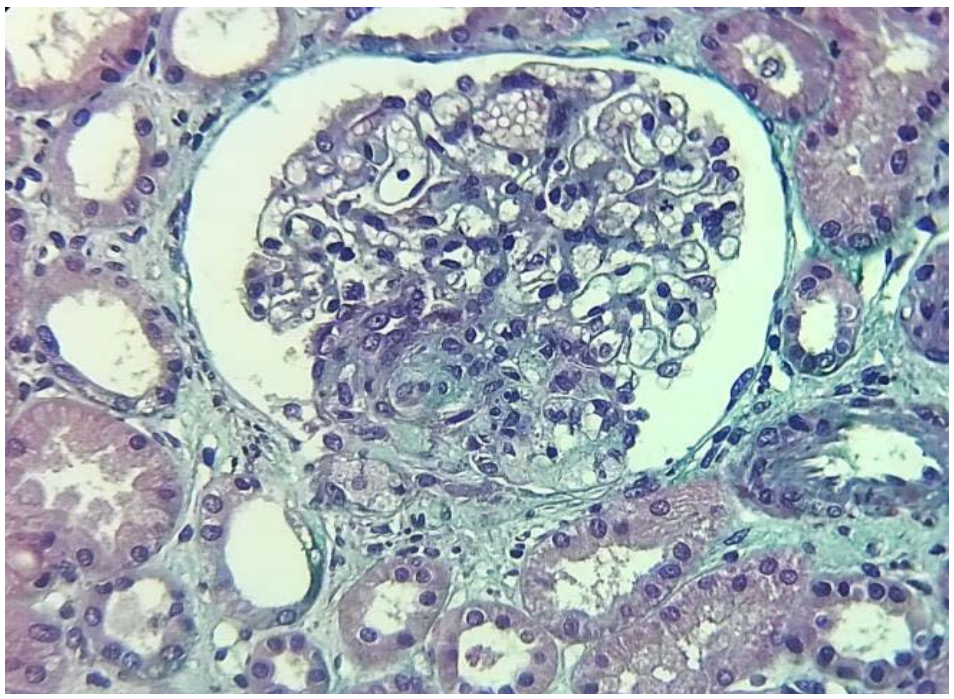

Figure 1. Classic FSGS Trichrome de Masson $\times 250$.

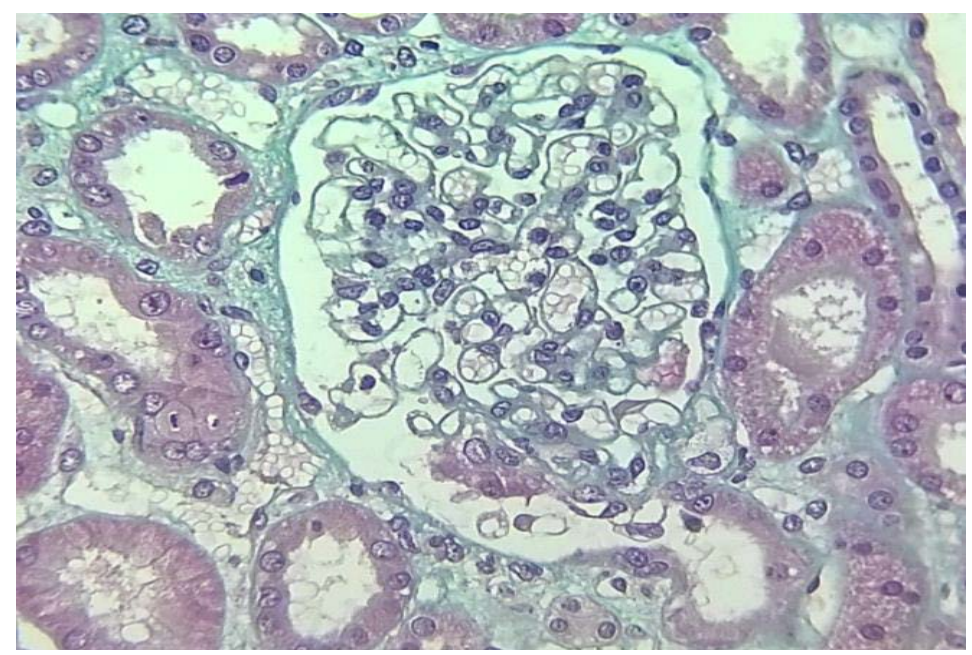

Figure 2. FSGS "tip lesion": the lesion is located at the tubular pole Trichrome de Masson $\times 250$. 


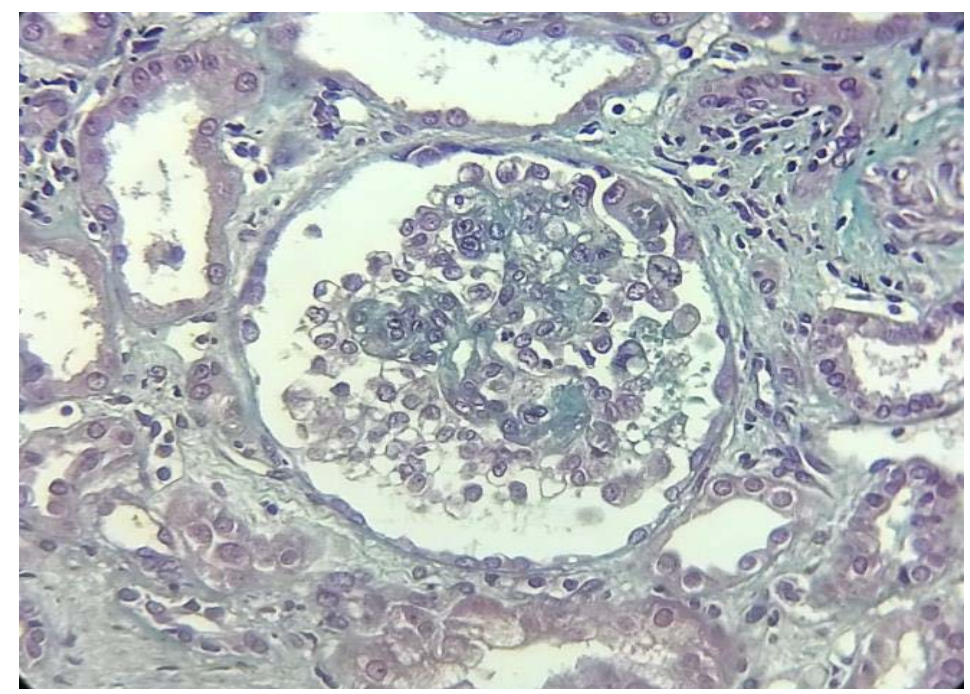

Figure 3. Collapsing FSGS: Retraction of flocculus Masson's Trichrome $\times 250$.

Among the patients in remission, 33.3\% had developed a relapse within an average of $15.4 \pm 9.1$ months. The number of relapses per patient was 1.43 (range 1 - 2) and the first episode was treated with a full-dose corticosteroid therapy. Corticosteroid-dependence was observed in 5 patients (11.1\%) with an average dose of $33 \mathrm{mg} / \mathrm{d}$. Cases of corticosteroid resistance and corticosteroid dependence were treated in second intention by immunosuppressive therapy in association with low dose of corticosteroid. Eight patients (7 cases of corticosteroid resistance and 1 case of relapse) were on cyclosporine with an average dose of $175 \pm 26.7 \mathrm{mg} /$ day and 6 had achieved remission. Azathioprine was administered to 4 patients and cyclophosphamide to 2 patients.

Two patients had progressed to ESRD, whose one to chronic hemodialysis. Infectious complications were observed in 11 patients or 19\% (Table 2). Inunivariate analysis, there was a statistically significant link between the male gender and the occurrence of a relapse with $\mathrm{p}=0.01(95 \% \mathrm{CI}=11.2[1.28-97.71])$ (Table 3). However, age, serum albumin, proteinuria, and tubulointerstitial and vascular lesions associated were not correlated with remission, corticosteroid resistance and corticosteroid dependence (Table 4).

\section{Discussion}

Primary FSGS is the lesion found in 35\% of cases of primary nephrotic syndrome in the United States [5]. In Africa, it is the 2nd cause of primitive glomerulonephritis [6]. Early diagnosis and knowledge of the factors of poor prognosis is essential for monitoring patients [4].

Our study involved 58 adult patients with primary FSGS. We found a young population with an average age of 30.74 years. Similar results were found in Morocco, Tunisia and India with respective ages of 35.8, 39.9 and 31.1 years [4] [6] [7]. We noted a clear male predominance, which corroborated with most of 
Table 2. Representation of the different types of complications.

\begin{tabular}{ccc}
\hline Types of complications & Workforce (n) & Percentage (\%) \\
\hline Respiratory infections & 5 & 8.62 \\
Skin infections & 3 & 5.17 \\
ESRD & 2 & 3.45 \\
Thromboembolic & 1 & 1.72 \\
Cortisonic impregnation & 1 & 1.72 \\
Lymphedema & 1 & 1.72 \\
Dehydration & 1 & 1.72 \\
Allergy to ACE inhibitors & 1 & 1.72 \\
Ulcerative syndrome & 1 & 1.72 \\
Dysenteric syndrome & 1 & 1.72 \\
Vomiting & 1 & 1.72 \\
Constipation & 1 & 1.72 \\
Death & 2 & 3.45 \\
\hline
\end{tabular}

Table 3. Correlation between characteristics patients and relapse.

\begin{tabular}{lccc}
\hline & & Remission & P-value \\
\hline Age (year) & $>30$ & $11(42.31 \%)$ & 0.21 \\
& $<30$ & $4(25 \%)$ & \\
Gender & $\mathrm{M}$ & $14(48.28 \%)$ & 0.01 \\
& $\mathrm{~F}$ & $1(7.68 \%)$ & 0.52 \\
Serum albumin $<20 \mathrm{~g} / \mathrm{L}$ & $10(35.71 \%)$ & 0.65 \\
Proteinuria $>3$ g/d & $10(30.3 \%)$ & - \\
Tubulointertital lesions & $4(17.39 \%)$ & 0.19 \\
Vascular lesions & $5(26.3 \%)$ &
\end{tabular}

Table 4. Correlation between characteristics patients and corticosteroid treatment responses.

\begin{tabular}{lcccc}
\hline & & Remission & Corticosteroid resistance & P-value \\
\hline \multirow{2}{*}{ Age (year) } & $>30$ & $26(78.79 \%)$ & $7(21.21 \%)$ & 0.5 \\
& $<30$ & $19(82.61 \%)$ & $4(17.39 \%)$ & \\
Gender & $\mathrm{M}$ & $33(82.5 \%)$ & $7(17.5 \%)$ & 0.38 \\
Serum albumin $<20 \mathrm{~g} / \mathrm{L}$ & $30(76.92 \%)$ & $9(23.08 \%)$ & 0.19 \\
Proteinuria $>3$ g/d & $34(75.56 \%)$ & $11(24.44 \%)$ & 0.34 \\
Tubulointertital lesions & $22(73.33 \%)$ & $8(26.67 \%)$ & 0.2 \\
\multicolumn{2}{c}{ Vascular lesions } & $17(73.91 \%)$ & $6(26.09 \%)$ & 0.27 \\
\hline
\end{tabular}

the studies done in Africa, Asia and America [4] [7] [8] [9]. The proportion of hypertensive patients was similar to that found by Moura in Brazil [10]. Micky J. CHUN in Chicago found a higher rate of hypertensive patients [11] and this dif- 
ference could be due to the younger age of our patients. The average GFR was close to those found by Troyanov in Canada [12] and Hong Ren in China [13]. In our series, the urinary protein average was approximately in agreement with the various studies made on this subject [4] [8] [10] [12]. The classical form was the most frequently found histological type and this is in agreement with most of the studies [4] [8] [14].

As recommended by KDIGO 2012, it is suggested that the high initial dose of corticosteroids be administered for at least 4 weeks and then continued at high dose corticosteroids up to a maximum of 16 weeks, or until the complete remission has been obtained [2]. In our series, the average dose of corticosteroids was close to that administered by Hong Ren in China [13]. The duration of the reduction in corticosteroid doses was consistent with those found in the literature [11] [13]. The similar efficacy between the use of calcineurin inhibitors and cyclophosphamide could explain the different choices of immunosuppressive drugs in the corticodependent and corticosteroid-resistant forms [4]. However, cyclophosphamide was less prescribed due to the frequency of complications related to this molecule. The low prescription of immunosuppressant in our study is linked to its high cost in our context.

Achieving remission is the ultimate goal in patients with primary FSGS. We found a higher remission rate compared to most studies [8] [10] [12] [15] [16]. This can be explained by our young population, which responds better to corticosteroid therapy. Our proportion of corticosteroid resistance was lower compared to other studies [4] [8] [12] [15] [17] [18] and this could be linked to the difference between the histological forms found and the young age of our patients. Bagchi in India found a rate of corticodependence similar to our study [4]. The proportion of relapse observed matches with the results obtained by Troyanov [12] and Bagchi [4] respectively. On the other hand, Moura in Brazil [10] and Huang in China [14] found relapse rates significantly lower than our study in $11.6 \%$ and $13.5 \%$ respectively. This difference would be due to the irregular monitoring of our patients and the higher proportions of complete remission in these studies. The evolution towards ESRD was more observed in our study compared to the others [4] [8] [10]. This difference could be explained by the size of the cohorts and the sensitivity to therapeutic responses, which varied from one study to another. The male gender had a statistically significant link with the occurrence of a relapse, which was in agreement with the study of Troyanov [12]. However, we did not find any factor associated with remission or corticosteroid resistance, such as corticosteroid dependence. Biomarkers such as suPAR and the G1 and G2 variants of APOL-1 have been recognized as predictors of the progression of FSGS [19] [20]. Their routine dosage would be a major advantage for the nephrologist in his therapeutic choices.

\section{Limits}

Our study being retrospective had certain limitations. This patient cohort was 
small. We did not demonstrate the impact of histologic variants and tubulointerstitial and vascular lesions. Though a significant number of patients may be corticoresistant, they would do well with the timely reduction of proteinuria using aggressive second-line immunosuppression. Calcineurin inhibitors therapy is effective but difficult to sustain in low-income countries, where healthcare is predominantly self-financed.

\section{Conclusion}

At the end of our study, we found that the evolution of primary FSGS is marked by a high frequency of relapse. The male gender was correlated with the occurrence of a relapse. However, the impact of certain factors has not been demonstrated. This is likely due to the limited sample size, the type of study, and the intricate roles of these different factors.

\section{Conflicts of Interest}

The authors declare no conflicts of interest regarding the publication of this paper.

\section{References}

[1] Korbet, S.M. (2002) Treatment of Primary Focal Segmental Glomerulosclerosis. Kidney International, 62, 2301-2310. https://doi.org/10.1046/j.1523-1755.2002.00674.x

[2] Kidney Disease Improving Global Outcomes (KDIGO) (2012) Glomerulonephritis Work Group: KDIGO Clinical Practice Guideline for Glomerulonephritis. Kidney International, 2, 139-274.

[3] Beaudreuil, S., Lorenzo, H.K., Elias, M., Obada, E.N., Charpentier, B. and Durrbach, A. (2017) Optimal Management of Primary Focal segmental Glomerulosclerosis in Adults. International Journal of Nephrology and Renovascular Disease, 10, 97-107. https://doi.org/10.2147/IJNRD.S126844

[4] Bagchi, S., Agarwal, S., Kalaivani, M., Bhowmik, D., Singh, G., Mahajan, S. and Dinda, A. (2016) Primary FSGS in Nephrotic Adults: Clinical Profile, Response to Immunosuppression and Outcome. Nephron, 132, 81-85. https://doi.org/10.1159/000442999

[5] Kitiyakara, C., Eggers, P. and Kopp, J.B. (2004) Twenty-One-Year Trend in ESRD Due to Focal Segmental Glomerulosclerosis in the United States. American Journal of Kidney Diseases, 44, 815-825. https://doi.org/10.1016/S0272-6386(04)01081-9

[6] Okpechi, I.G., Ameh, O.I., Bello, A.K., Ronco, P., Swanepoel, C.R. and Kengne, A.P. (2016) Epidemiology of Histologically Proven Glomerulonephritis in Africa: A Systematic Review and Meta-Analysis. PLoS ONE, 11, e0152203. https://doi.org/10.1371/journal.pone.0152203

[7] Eljouehari, M., Flayou, K., Raoundi, O., Benamar, L., Rhou, H., Bayahia, R. and Ouzeddoun, N. (2015) Anatomopathological and Evolutionary Profile of Primary Idiopathic Segmental and Focal Hyalinosis. Nephrology \& Therapeutics, 11, 379. https://doi.org/10.1016/j.nephro.2015.07.352

[8] Hadded, S., Harzallah, A., Karoud, H., Cheikh, M., Goucha, R., Barbouch, S., Benhamida, F., Gorsane, I. and Benabdallah, T. (2016) Profil évolutif de la hyalinose 
segmentaire et focale de l'adulte. Néphrologie \& Thérapeutique, 12, 362-363. https://doi.org/10.1016/j.nephro.2016.07.208

[9] Niang, A., Dial, C., Ka, E.F., Lèye, A., Pouye, A., Ka, M.M., et al. (2008) Nephroticsyndrom with Focal and Segmental Glomerulosclerosis in Dakar: Epidemiological and Clinicopathological Characteristics (About 134 Cases). Dakar Médical, 53, 45-51.

[10] Moura, L.R.R., Franco, M.F. and Kirsztajn, G.M. (2015) Minimal Change Disease and Focal Segmental Glomerulosclerosis in Adults: Response to Steroids and Risk of Renal Failure. Jornal Brasileiro de Nefrologia, 37, 475-480. https://doi.org/10.5935/0101-2800.20150075

[11] Chun, M.J., Korbet, S.M., Schwartz, M.M. and Lewis, E.J. (2004) Focal Segmental Glomerulosclerosis in Nephrotic Adults: Presentation, Prognosis, and Response to Therapy of the Histologic Variants. Journal of the American Society of Nephrology, 15, 2169-2177. https://doi.org/10.1097/01.ASN.0000135051.62500.97

[12] Troyanov, S., Wall, C.A., Miller, J.A., Scholey, J.W. and Cattran, D.C. (2005) Focal and Segmental Glomerulosclerosis: Definition and Relevance of a Partial Remission for the Toronto Glomerulonephritis Registry Group. Journal of the American Society of Nephrology, 16, 1061-1068. https://doi.org/10.1681/ASN.2004070593

[13] Ren, H., Shen, P.Y., Li, X., Pan, X.X., Zhang, Q.Y., Feng, X.B., Zhang, W. and Chen, N. (2013) Treatment and Prognosis of Primary Focal Segmental Glomerulosclerosis. Contributions to Nephrology, 181, 109-118. https://doi.org/10.1159/000348468

[14] Huang, J.N., Lin, L., Xie, J.Y., Li, X., Shen, P.Y., Pan, X.X., and Chen, N. (2018) Glucocorticoids in the Treatment of Patients with Primary Focal Segmental Glomerulosclerosis and Moderate Proteinuria. Clinical and Experimental Nephrology, 22, 1315-1323.

[15] Ponticelli, C., Edefonti, A., Ghio, L., Rizzoni, G., Rinaldi, S., Gusmano, R., et al. (1993) Cyclosporin versus Cyclophosphamide for Patients with Steroid-Dependent and Frequently Relapsing Idiopathic Nephrotic Syndrome: A Multicentre Randomized Controlled Trial. Nephrology Dialysis Transplantation, 8, 1326-1332.

[16] Agarwal, S.K., Dash, S.C., Tiwari, S.C. and Bhuyan, U.N. (1993) Idiopathic Adult Focal Segmental Glomerulosclerosis: A Clinicopathological Study and Response to Steroid. Nephron, 63, 168-171. https://doi.org/10.1159/000187177

[17] Stirling, C.M., Mathieson, P., Boulton-Jones, J.M., Feehally, J., Jayne, D., Murray, H.M., et al. (2005) Treatment and Outcome of Adult Patients with Primary Focal Segmental Glomerulosclerosis in Five UK Renal Units. QJM, 98, 443-449. https://doi.org/10.1093/qjmed/hci072

[18] Swarnalatha, G., Ram, R., Ismal, K.M., Vali, S., Sahay, M. and Dakshinamurty, K.V. (2015) Focal and Segmental Glomerulosclerosis: Does Prognosis Vary with the Variants? Saudi Journal of Kidney Diseases and Transplantation, 26, 173-181. https://doi.org/10.4103/1319-2442.148772

[19] Campbell, K.N. and Tumlin, J.A. (2018) Protecting Podocytes: A Key Target for Therapy of Focal Segmental Glomerulosclerosis American Journal of Nephrology, 47, 14-29. https://doi.org/10.1159/000481634

[20] Cattran, D.C. and Rao, P. (1998) Long-Term Outcome in Children and Adults with Classic Focal Segmental Glomerulosclerosis. American Journal of Kidney Diseases, 32, 72-79. https://doi.org/10.1053/ajkd.1998.v32.pm9669427 